\title{
Genetic editing of the virulence gene of Escherichia coli using the CRISPR system
}

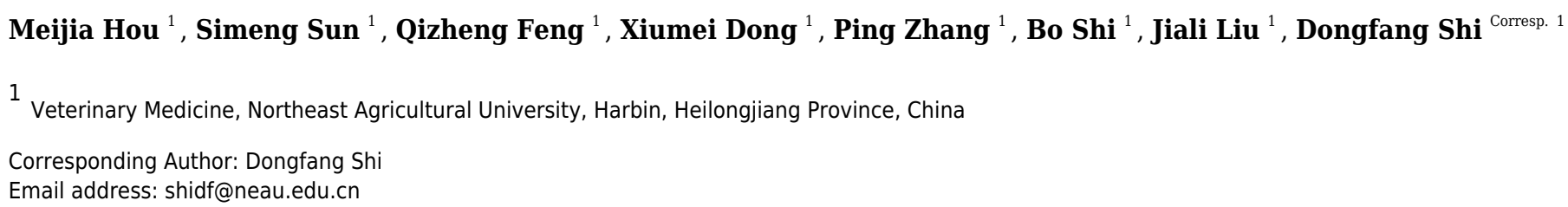

Clustered regularly interspaced short palindromic repeats (CRISPR)/Cas9 is an emerging gene-editing technology that is widely used in prokaryotes and eukaryotes. It can realize the specific manipulation of the genome efficiently and accurately. CRISPR/Cas9 coupled $\lambda$ Red recombination technology was used to perform genome editing in different genes. For finding an efficient method to edit the virulence genes of enterotoxigenic $E$. coli (ETEC), the two-plasmid system was used. The coding sequence (CDS) region of the estA, eltl, estB, eltllc1, and faeG locus were deleted. The coding region of estB was substituted with est $A$. Gene recombination efficiency ranged from 0 to $77.78 \%$ when the length of the homology arm was from 50 to $300 \mathrm{bp}$. Within this range, the longer the homology arm, the higher the efficiency of genetic recombination. The results showed that this system can target virulence genes located in plasmids and on chromosomes of ETEC strains. A single base mutation was performed by two-step gene fragment replacement. This study lays the foundation for research on virulence factors and genetic engineering of vaccines for ETEC. 
1 Genetic editing of the virulence gene of Escherichia coli using the CRISPR system

2

3

4

5 Meijia Hou, Simeng Sun, Qizheng Feng, Xiumei Dong, Ping Zhang, Bo Shi, Jiali Liu, Dongfang

6 Shi

7

8 9

10 Corresponding Author:

11 Dongfang Shi,

12 Changjiang Road 600, Harbin, Heilongjiang Province, 150030, China

13 Email address: shidf@neau.edu.cn

14

15

16

17

18

19

20

21

22

23

24

25

26

27

28

29

30

31

32

33

34 


\section{Abstract}

36 Clustered regularly interspaced short palindromic repeats (CRISPR)/Cas9 is an emerging geneediting technology that is widely used in prokaryotes and eukaryotes. It can realize the specific manipulation of the genome efficiently and accurately. CRISPR/Cas9 coupled $\lambda$-Red recombination technology was used to perform genome editing in different genes. For finding an efficient method to edit the virulence genes of enterotoxigenic E. coli (ETEC), the two-plasmid system was used. The coding sequence (CDS) region of the estA, elt I, estB, elt IIc1, and faeG locus were deleted. The coding region of $e s t B$ was substituted with $e s t A$. Gene recombination efficiency ranged from 0 to $77.78 \%$ when the length of the homology arm was from 50 to 300 bp. Within this range, the longer the homology arm, the higher the efficiency of genetic recombination. The results showed that this system can target virulence genes located in plasmids and on chromosomes of ETEC strains. A single base mutation was performed by twostep gene fragment replacement. This study lays the foundation for research on virulence factors and genetic engineering of vaccines for ETEC.

Keywords: CRISPR/Cas9, virulence genes, ETEC, single base mutation, CDS

Introduction

Genome editing refers to the introduction of engineered mutations into specific loci of a target genome by genome editing techniques. In general, the current genome editing methods can be divided into three categories: the first category of genome editing relies on Cre (cause recombination enzyme)/loxP and Flp (Flippase recombination enzyme)/FRT (FLP recombination target); the second category is marker-free editing by the 'pop-in/pop-out' method; and the third category of genome editing relies on nucleases that recognize specific sequences.

Cre/lox $P$ originates from the $\mathrm{P} 1$ phage. Cre is a recombinase that recognizes a specific genomic sequence called the loxP site. Cre recombinase removes sequences located between loxP sites (Abremski \& Hoess 1985). Flp/FRT originated from a plasmid in yeast. Flp is a recombinase similar to Cre, and its recognition site is named FRT (Hoang et al. 1998; Kilby et al. 1993). The implementation of Cre/loxP and Flp/FRT technologies is generally divided into two parts. First, the marker gene with the screening function is integrated into the genome to complete the transformation of the target region, and then the resistance marker gene is excised 
66

67

68

69

70

71

72

73

74

75

76

77

78

79

80

81

82

83

84

85

86

87

88

89

90

91

92

on the genome, which is very unfavorable for the study of functional genes or multigene continuous operation.

To achieve seamless editing of the genome, the researchers chose a genetic framework with a positive screening function and a reverse screening function through two rounds of genetic manipulation. In addition, homologous recombination between the two rounds of genome editing required the expression of the exogenous $\lambda$-Red recombinase.

The CRISPR/Cas-mediated genome editing technology that has emerged in recent years is the third generation of endonuclease-dependent genome editing technologies. The principle is based on the mechanism of bacterial resistance to the invasion of foreign phage DNA (Sander \& Joung 2014). Compared with ZFNs and TALENs, CRISPR/Cas has the advantages of simple operation, a short operating cycle and low technical requirements for the operator. The CRISPR/Cas9 system has been successfully applied in diverse organisms including but not limited to humans (Drost et al. 2015), mice (Aida et al. 2015), zebrafish (Varshney et al. 2016), C. elegans (Shen et al. 2014), rice (Yin et al. 2017), E. coli (Jiang et al. 2013), and Saccharomyces cerevisiae (Brune et al. 2018), Chlamydomonas chloroplasts (Yoo et al. 2020).

For gene editing in E. coli, a three-plasmid system with highly efficient recombination was developed (Pyne et al. 2015). Subsequently, a two-plasmid system was constructed which included pCas containing the Cas9 protein and pTargetF containing the sgRNA (single guide RNA) (Jiang et al. 2015). However, the two-plasmid system still requires two steps in the process of curing the plasmid. To facilitate operation, a single-plasmid system was constructed which included Cas9 and sgRNA on one plasmid and it could be cured in one step by a temperature-sensitive element (Zhao et al. 2016). The CRISPR/Cas-mediated genome editing technology has been used in various articles for the purposes of deleting or replacing different virulence genes. However, we haven’t read any report on the editing of Escherichia coli virulence genes yet. At present, only genetic engineering model strains such as E. coli K12, DH5 $\alpha$ and BL21 have been selected for CRISPR research. ETEC is one of the leading causes of bacterial diarrhea in humans and piglets. ETEC colonizes the intestines through the pili and then 
93 produces enterotoxin, which causes electrolyte disturbances that cause diarrhea. ETEC affects

94 intestinal immunity through NF- $\mathrm{B}$ and MAPK signaling pathways (Yang et al. 2016). Liu

95 studied several virulence genes of ETEC and constructed an attenuated strain with the $\lambda$-Red

96 recombination system in our laboratory, but the recombination efficiency was low (Liu et al.

97 2015). Due to the complicated operation steps of three-plasmid system and the high construction

98 cost of single-plasmid system, we selected the two-plasmid system for genetic editing in ETEC.

99 The aim of this study was to find an efficient editing method for virulence genes located on

100 chromosomes and in plasmids. This study paved the way for further research on virulence gene

101 function, immune mechanism and genetically engineered vaccines of ETEC.

102

103 Materials and Methods

104 Bacterial strains, plasmids, oligonucleotides, and growth conditions

105 The bacterial strains and plasmids used in this work are listed in Table 1. E. coli Trans1-T1

106 was used as a cloning host. The ETEC strains of E. coli O141:K85, E. coli O142 and E. coli

107 DN1502 were used in the genome engineering after the susceptibility test, especially kanamycin

108 and spectinomycin. E. coli O141:K85 (CVCC197) was a porcine ETEC field-isolated strain

109 deposited in the Chinese Veterinary Culture Collection Center. E. coli O142 and E. coli DN1502

110 were isolated from diarrhea claves, and their virulence were tested in our laboratory (Liu et al.

111 2015; Liu et al. 2014). Y-1 mouse adrenocortical cells were purchased from Shanghai Cell Bank,

112 Chinese Academy of Sciences. Based on the gene sequence published in NCBI and the pTargetF

113 plasmid sequence published in Addgene, primers were designed using Primer 5.0 software, and

114 the N20 sequence was designed using online software. E. coli were grown in lysogeny broth ( $1 \%$

115 tryptone, $0.5 \%$ yeast extract, $1 \% \mathrm{NaCl})$ at $30{ }^{\circ} \mathrm{C}$ or $37^{\circ} \mathrm{C}$. Kanamycin $(30 \mu \mathrm{g} / \mathrm{mL})$, ampicillin

$116(100 \mu \mathrm{g} / \mathrm{mL})$, and spectinomycin $(250 \mu \mathrm{g} / \mathrm{mL})$ were added to the medium as appropriate. L-

117 arabinose $(1.5 \mathrm{mg} / \mathrm{mL}$ final concentration) was used for $\lambda$-Red induction when necessary.

\section{Plasmid construction}

119 We used the plasmid constructed by Sheng Yang 's laboratory (Jiang et al. 2015) to edit the 120 virulence gene of ETEC. These virulence genes included type II heat-labile enterotoxin c1 
121 subtype LT-IIc1 gene (elt IIcl) located on the chromosome; type I heat-labile enterotoxin LT-I

122 gene (elt I), type I heat-stable enterotoxin gene STa (est $A$ ) and type II heat-stable enterotoxin 123 STb gene (estB) located on the pEnt plasmid; and FaeG subunit gene ( $f a e G)$ of K88 fimbriae 124 located on other plasmids. First, the homology arms were amplified using the primers pairs 125 DonorL-F/R and DonorR-F/R to form DonorL and DonorR. $2 \mu \mathrm{L}$ bacterial solution were used as 126 DNA sample and subjected to PCR reactions where each reaction in $25 \mu \mathrm{L}$ consisted of $16 \mu \mathrm{L}$ of 127 deionized water, $1 \mu \mathrm{L}$ of forward primer, $1 \mu \mathrm{L}$ of reverse primer, $2 \mu \mathrm{L} 2.5 \mathrm{mM}$ dNTPs, $2.5 \mu \mathrm{L}$ 128 6X DNA Buffer and 0.5 $\mu$ L EasyTaq DNA Polymerase (TransGen, 126 Beijing, China). The 129 PCR amplification was performed as follows: initial denaturation, $94{ }^{\circ} \mathrm{C}$ for $5 \mathrm{~min} ; 30$ cycles of $13094{ }^{\circ} \mathrm{C}$ for $30 \mathrm{~s}, 55^{\circ} \mathrm{C}$ for $30 \mathrm{~s}$ and $72{ }^{\circ} \mathrm{C}$ for $45 \mathrm{~s}$; final polymerization $72{ }^{\circ} \mathrm{C}$ for $7 \mathrm{~min}$. The PCR 131 products were separated on $0.8 \%$ agarose gel by electrophoresis. The DNA bands were cut out 132 of the gel and extracted using the Gel Extraction Kit (Omega, Norcross, GA, USA). Then, N20 133 and sgRNA fragments were amplified from pTargetF by the primer pair psgRNA-F/R. The 134 targeted N20 was designed according to GenBank ID with the help of a website 135 (https://zlab.bio/guide-design-resources).

136 The homologous arms with N20 and sgRNA fragments were ligated into the pMD19T 137 (Taraka, Dalian, China) vector after overlap PCR. The ligation system contained $1 \mu \mathrm{L}$ of $138 \mathrm{pMD19T}, 3 \mu \mathrm{L}$ of DNA fragments, $5 \mu \mathrm{L}$ of Solution I, and $1 \mu \mathrm{L}$ of deionized water. Mixed the 139 above reagents and left at $16^{\circ} \mathrm{C}$ for $1 \mathrm{~h}$. The ligation product was introduced into DH5 $\alpha$. After 140 sequencing, the correct recombinant pMD19T was named as repMD19T. repMD19T and 141 pTargetF were digested with SpeI and XhoI, and then the digested small fragment of repMD19T 142 and large fragment of pTargetF were ligated overnight at $16{ }^{\circ} \mathrm{C}$ using $\mathrm{T} 4$ ligase. In this way, 143 pTarget- $\Delta$ elt $I$, pTarget- $\Delta e s t B$, pTarget- $\Delta e l t ~ I I c 1_{(400)}$, pTarget- $\Delta e s t A$ and pTarget- $\Delta$ fae $G$ were 144 constructed. pTarget- $\triangle e s t B::$ est $A$ was constructed by inserting the overlap PCR fragment into 145 SpeI/XhoI-digested pTargetF, which was amplified with primers P9/P10, P11/P41, P42/P43, and

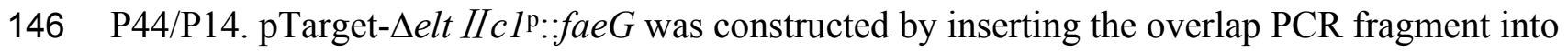


147 SpeI/XhoI-digested pTargetF, which was amplified with primers P17/P45, P46/P47, P48/P49,

148 and P50/P51. pTarget- $\Delta$ faeG::elt IIc $1^{193}$ was constructed by inserting the overlap PCR fragment

149 into SpeI/XhoI-digested pTargetF, which was amplified with primers P33/P45, P46/P52, and

150 P53/P51. pTarget- $\Delta$ elt $I I c 1_{(300)}$, pTarget- $\Delta$ elt $I I c 1_{(200)}$, pTarget- $\Delta$ elt $I I c l_{(100)}$, and pTarget-

$151 \Delta e l t / I c 1_{(50)}$ was constructed by inserting various lengths of homology arm amplified with

152 pTarget- $\Delta e l t I I c l$ as a template into $X b a \mathrm{I} / X h o I$-digested pTarget- $\Delta e l t ~ I / c 1$, respectively.

153 Genome editing procedure

154 ETEC was used in all mutagenesis experiments. The electro competent cells of original 155 bacterial were prepared as follow steps. One single colony of ETEC from an LB agar plate was 156 cultured overnight in $3 \mathrm{~mL}$ of LB medium at $37^{\circ} \mathrm{C} .1 \mathrm{~mL}$ of overnight culture was inoculated 157 and grown in $100 \mathrm{~mL}$ of $\mathrm{LB}$ medium at $37^{\circ} \mathrm{C}$ until the optical density at $600 \mathrm{~nm}\left(\mathrm{OD}_{600}\right)$ reached $1580.6 \sim 0.8$. Then, the cells were centrifuged at 5,000 rpm for $15 \mathrm{~min}$ at $4{ }^{\circ} \mathrm{C}$ and washed three 159 times with ice-cold 10\% glycerol. After the final wash, $1 \mathrm{~mL}$ of ice-cold $10 \%$ glycerol was added 160 to the tube to resuspend the cells, which were dispensed into a frozen EP tube per $100 \mu \mathrm{L}$. pCas 161 was introduced into the competent cells. Transformation was done by electroporation using the 162 ECM 399 Electroporation System (BTX). Electro competent cells harboring pCas were prepared 163 by growing a single colony in $3 \mathrm{~mL}$ of $\mathrm{LB}$ medium with $30 \mu \mathrm{g} / \mathrm{mL}$ kanamycin at $30{ }^{\circ} \mathrm{C}$. One 164 milliliter of overnight culture was inoculated and grown in $100 \mathrm{~mL}$ of $\mathrm{LB}$ medium at $30{ }^{\circ} \mathrm{C}$. L165 arabinose was added to a concentration of $1.5 \mathrm{mg} / \mathrm{mL}$ at $0.2 \sim 0.3$ of $\mathrm{OD}_{600}$. Then, the cells were 166 harvested at an $\mathrm{OD}_{600}$ of $0.6 \sim 0.8$ by centrifugation, washed three times with ice-cold $10 \%$ 167 glycerol, and concentrated approximately 100 -fold. $100 \mu \mathrm{L}$ of electro competent cells were 168 mixed with $300 \mathrm{ng}$ of pTarget series plasmids. Electroporation was performed in a 2-mm gap

169 electroporation cuvette (BTX) at $2.5 \mathrm{kV}$. The electro transformed cells were suspended 170 immediately in $1 \mathrm{~mL}$ of $\mathrm{LB}$ medium and recovered at $30^{\circ} \mathrm{C}$ for $1 \mathrm{~h}$, after which they were plated 171 on LB agar containing kanamycin and spectinomycin and incubated overnight at $30^{\circ} \mathrm{C}$. A single 
172 colony was picked and inoculated into LB medium containing kanamycin and spectinomycin for 173 the next tests. Transformants were identified by PCR and DNA sequencing.

\section{Plasmid curing}

175 For pTarget curing, the identified bacteria were streaked onto LB plates containing 176 kanamycin and spectinomycin and cultured overnight at $30^{\circ} \mathrm{C}$. Then, a single colony was picked 177 and inoculated into $3 \mathrm{~mL}$ of LB medium containing kanamycin and $1 \mathrm{mM}$ isopropyl- $\beta$-D178 thiogalactoside (IPTG) and cultured at $30{ }^{\circ} \mathrm{C}$ for $16 \mathrm{~h}$. The culture was confirmed as cured by 179 ensuring the sensitivity to spectinomycin $(250 \mu \mathrm{g} / \mathrm{mL})$ and by PCR method. For pCas curing, the 180 identified bacteria were streaked on an LB plate containing kanamycin and cultured at $30{ }^{\circ} \mathrm{C}$ 181 overnight. Then, a single colony was picked and placed in $3 \mathrm{~mL}$ nonselective LB medium and 182 cultured at $37^{\circ} \mathrm{C}$ for $16 \mathrm{~h}$. The cultures were confirmed as cured by measuring their sensitivity to 183 kanamycin $(30 \mu \mathrm{g} / \mathrm{mL})$ and PCR method. The gene editing theory and process are shown in Fig. 1841 and Fig. 2, respectively.

185

186

\section{Results}

\section{Editing of the ETEC virulence gene}

We constructed single-gene deficient and multi-genes deficient ETEC strains. For a single 189 gene deletion, $10 \%$ of the transformants showed the expected genotype when elt I was deleted 190 from E. coli O141:K85 (Table 2, experiment 1). The efficiency of knocking out estB and faeG 191 from E. coli $\mathrm{O} 141: \mathrm{K} 85$ was 1.4\% and 23.8\%, respectively. We tested the continuous virulence 192 gene deletion ability of this two-plasmid system in ETEC. Three virulence genes of E. coli 193 O141:K85 were deleted with pTarget- $\Delta$ elt I, pTarget- $\Delta$ estB, pTarget- $\Delta$ fae $G$. Then, E. coli obtained (Table 2, experiments $1,3,5$ ). These results proved that the system can continuously edit the virulence genes of ETEC.

Comparing the deletion of different virulence genes, we found that the mutation rate was lower than $25 \%$ when the length of the homology arm fragment was less than $200 \mathrm{bp}$ (Table 2, 
199

200

201

202

203

204

205

206

207

208

209

210

211

212

213

214

215

216

217

218

219

220

221

222

223

experiments $1,2,4)$. But the mutation rate increased significantly to more than $60 \%$ when the length of the homology arm was over 300 bp (Table 2, experiments 6-10). Besides gene deletion, we also carried out gene replacement. The mutation efficiency was $14.14 \%$ to replace $e s t B$ with estA (Table 2, experiment 6).

For point mutations, pTarget- $\Delta$ elt IIcl::faeG was transformed into E. coli DN1502

harboring pCas to replace elt IIcl with faeG to obtain E. coli DN1502 $\Delta$ elt IIcl::faeG. We constructed pTarget- $\Delta$ fae $G:$ elt $I / c 1^{193}$ which sgRNA targeted fae $G$ and contained a mutant elt IIcl fragment. Then, pTarget- $\Delta$ fae $G:$ elt $I I c 1^{193}$ was electrotransformed into the bacteria obtained in the previous step. This changed the 193rd amino acid codon of elt IIcl from CTG to CTC, forming a SacI cleavage site $\left(\mathrm{GAG}^{192} \mathrm{CTC}^{193}\right)$. These results proved that continuous gene editing and point mutations can be achieved (Table 2, experiments 9, 10).

Since the efficiency of gene deletion ranged, there is necessary to further explore whether the size of the homologous arm was related to it. We designed the pTarget- $\Delta$ elt IIcl series with 300 bp, 200 bp, 100 bp, 50 bp homologous arms, combined with pTarget- $\Delta$ elt IIc1 $1_{(400)}$ (Table 2, experiments $8,11-14)$. By comparison, the gene editing efficiency was the highest when the homology arm was approximately $300 \mathrm{bp}$. The homology arms size, deletion fragment length and recombination efficiency of the target genes are listed in Table 2. Agarose gel electrophoresis of colony PCR is shown in Fig. 3.

\section{Plasmid curing}

For the pTarget series plasmid curing, the effects of IPTG concentration and incubation time were tested. IPTG $(0.5 \mathrm{mM}$ and $1 \mathrm{mM})$ was used to induce the Ptrc promoter to guide sgRNA to target the pTarget series plasmid. Then, cells were cultured at $30{ }^{\circ} \mathrm{C}$ for $8,10,12,14$ and $16 \mathrm{~h}$. The results showed that $1 \mathrm{mM}$ IPTG induction with $8 \mathrm{~h}$ culture made the optimal combination. The colonies on the kanamycin-containing plates grew normally, while there was 
224 no visible growth on the spectinomycin-containing plates. The pTarget series plasmids were

225 verified to be eliminated by colony PCR with primers P68/P69. pTarget series plasmids could be 226 cured in all of the genetically edited strains.

227 For the pCas plasmid curing, incubation times were tested for 8, 10, 12, 14, and $16 \mathrm{~h}$. The 228 results showed that $8 \mathrm{~h}$ for curing pCas was enough. The colonies grew normally on the LB 229 plates, and there was no visible growth on the kanamycin plates, indicating that the elimination 230 of pCas was successful. pCas could be cured in all of the genetically edited strains. Agarose gel 231 electrophoresis of colony PCR with primers P70/P71 after plasmid curing is shown in Fig. 4.

\section{Discussion}

The CRISPR/Cas gene operating system has made great progress in the field of eukaryotes, but it is not widely used in prokaryotes. The two-plasmid system combined the CRISPR/Cas9 system and the $\lambda$-Red recombination to achieve target editing in the E. coli genome (Jiang et al. 2015), and the recombination efficiency was greatly improved. In this system, the temperaturesensitive plasmid pCas expressed Cas9, Exo, Bet, and Gam proteins. The last three proteins mediated homologous recombination in the $\lambda$-Red system. pTargetF expressed an sgRNA sequence that specifically recognized the target site. There is an IPTG-induced transcription of sgRNA on pCas, which is directed to the replicon pMB1 of pTargetF. Therefore, cas9+sgRNA cleaves pMB1 to cleave and eliminate pTargetF.

To date, model strains such as E. coli K12 and E. coli BL21 (DE3) have been employed

243 when using CRISPR/Cas in E. coli for genetic manipulation. However, there have been no 244 reports of genetic manipulation in wild-type E. coli. In this study, we focus on the application and efficiency of the CRISPR/Cas system in wild-type ETEC virulence genes.

This two-plasmid system introduces Red recombination technology into CRISPR. The Gam 247 protein can inhibit the RecBCD exonuclease of the host cell from degrading exogenous linear DNA. That made linear fragment could be used as the donor DNA. In fact, we tried to use linear fragment as the donor DNA early in the experiment. But there were no expected results. In 
251 al. 2015). This is consistent with the results of our actual operation. Thus, donor DNA was 252 assembled into pTarget in this study.

253 We tested whether continuous gene knockout can be performed in wild-type E. coli. After

254 deleting single gene elt I, estB, and fae G from the original E. coli O141:K85 respectively, we

255 successfully deleted the three genes consecutively in the bacteria. The deletion efficiency did not 256 change significantly. This indicated that the two-plasmid system is efficient tool for editing 257 virulence genes of ETEC in the laboratory.

258 We also achieved a single base mutation in elt IIcl in E. coli DN1502 by two rounds of 259 substitutions in the same position. This changed the codon of the 193rd amino acid (leucine) of 260 elt IIc1 from CTG to CTC where a SacI restriction enzyme cutting site emerged. This operation 261 has not been reported before our study. It proved the feasibility of continue substitution at the 262 same position in ETEC, and improved the application of the two-plasmid system.

263 Because we wanted to delete the complete CDS region of the virulence gene, the size of the 264 deletion fragment depended on the target gene itself. Some published sequences have only the 265 CDS region or are only slightly longer than the CDS region. The size of homology arm was 266 affected by sequence published in GenBank (Table 3). To explore the effect of the length of the 267 homology arm on the recombination efficiency, we designed 5 plasmids to knock out elt IIcl. It 268 was found that the longer the homology arm, the higher editing efficiency when the deletion 269 fragment length was the same. The deletion efficiency was the highest when the length of the 270 homology arm was approximately $300 \mathrm{bp}$. The toxicity of E. coli was significantly reduced after 271 the virulence gene was deleted. Relevant experiments and results were shown in supplementary 272 materials. Berger and co-workers analyzed the pAA primary transcriptome using differential 273 RNA sequencing and provided novel insights into its virulence gene expression and regulation 274 (Berger et al. 2016). A recent study showed that in patients with lung adenocarcinoma, patients 275 with lymph node metastasis had significantly elevated expression of long non-coding RNA than 276 patients with non-lymph node metastases. This indicated that long noncoding RNAs could be 
277 seen as candidate diagnostic and prognostic biomarkers for lung adenocarcinoma (Wang et al. 278 2019). Does the non-coding region affect the toxicity of ETEC? Is the virulence gene transcribed 279 if the promoter is deleted? These questions are interesting and worthy of further exploration.

280 The elt I, estA, estB and faeG locous are located on the plasmid of E. coli, and the elt IIcI 281 loci is located on the E. coli chromosome. It demonstrated that the two-plasmid-based CRISPR282 Cas9 system can target genes in plasmids and chromosomes, which was important to edit 283 virulence genes in ETEC.

284 To identify the recombinant strain by PCR, the pair of primers on the outside of the 285 homology arm was required. If homologous arm primers were used, it would result in false 286 positives. Because the pTarget plasmid with the homologous arm was not eliminated at this time. 287 The specificity of the CRISPR/Cas9 system depends mainly on sgRNA (Alkan et al. 2018;

288 Fu et al. 2014). The designed sgRNA may form a mismatch with nontarget DNA sequences, 289 resulting in unintended gene mutations, that are called off-target effects (Zhang et al. 2015). The 290 off-target mutations can cause genomic instability and disrupt the function of other normal genes 291 (Hsu et al. 2013; Mali et al. 2013). The off-target effect of Cas9 has been reported frequently in eukaryotes (Fu et al. 2013; Hsu et al. 2013). When we knocked out the estB, the first selected 293 colony of N20 did not complete the knockout task. Another colony of N20 was replaced to 294 continue and then succeeded. To reduce the off-target effects of Cas 9 in this study, it was best to 295 ensure that the 12 bases at the 3 ' end of the N20 sequence were highly specific to the genome (Jiang et al. 2013; Jiang et al. 2015). Existing online sgRNA design tools are not specifically targeted at ETEC. The evaluation of sgRNA off-target probability is based on E. coli K12 MG1655 instead of ETEC. It might lead to inaccurate evaluation of sgRNA off-target probability. From this current experimental results, the knockout efficiency can meet our requirements for gene editing.

The two-plasmid CRISPR/Cas system gives us more convenient conditions to study ETEC.

302 The two-plasmid CRISPR/Cas system gives us more convenient conditions to study ETEC. It 303 could be used to explore amino acids that affected virulence through site-directed mutations. And 
304 it also could be used to display foreign proteins on outer membrane or fimbriae of ETEC to 305 stimulate the body to produce antibodies. We believe that the two-plasmid system will be more 306 widely adopted following the further research.

307

308

309

310

311

312

313

314

315

316

317

318

319

320

321

322

323

324 325

326

327

328

329

330

331

\section{Conclusions}

ETEC is one of the important pathogens causing human and animal diarrhae. But the researches of its virulence genes were affected due to the lack of efficient gene editing tools. In this study, we explored the validity of the two-plasmid system of CRISPR/Cas for editing the virulence genes in ETEC. The results show that the two-plasmid system of CRISPR/Cas used in this study can edit the virulence genes on the ETEC plasmids and chromosome for deleting, replacing, and mutating. The editing efficiency is closely related to the homologous arm length, and the efficiency is the highest when the length of the homology arm is approximately $300 \mathrm{bp}$. This system can also be used for single base mutation through two rounds of replacement at the same position. These studies about how to quickly and efficiently perform gene editing in ETEC using the two-plasmid-based CRISPR-Cas9 system lay the foundation for further research on the roles of virulence genes in pathogenicity, antigenicity and adjuvanticity, and mutation of virulence genes for genetically engineering a vaccine of ETEC.

\section{Acknowledgments}

Financial support for this study was provided by grants from the National Science and Technology Support Project (2012BAD12B03-3, 2012BAD12B05-2) and the Science and Technology Planning Project of Heilongjiang Province (GC12B303). The authors are grateful to Pro. Sheng Yang (Key Laboratory of Synthetic Biology, Institute of Plant Physiology and Ecology, SIBS, CAS, Shanghai, China) for his kind provision of pCas and pTargetF and his patient guidance. His protocol has given us much help, and we have great convenience in experimentation. The plasmids pCas and pTargetF described in his work have been deposited in Addgene (http://www.addgene.org/) under No. 62225 and No. 62226, respectively. We also thank Pro. Yudong Cui for providing E. coli O142. 


\section{References}

336

Abremski K, and Hoess R. 1985. Phage P1 Cre-loxP site-specific recombination. Effects of DNA supercoiling on catenation and knotting of recombinant products. $J$ Mol Biol 184:211-220. DOI: 10.1016/0022-2836(85)90374-2

Aida T, Chiyo K, Usami T, Ishikubo H, Imahashi R, Wada Y, Tanaka KF, Sakuma T, Yamamoto T, and Tanaka K. 2015. Cloning-free CRISPR/Cas system facilitates functional cassette knock-in in mice. Genome Biol 16:87. DOI: 10.1186/s13059-0150653-x

Berger P, Knodler M, Forstner KU, Berger M, Bertling C, Sharma CM, Vogel J, Karch H, Dobrindt U, and Mellmann A. 2016. The primary transcriptome of the Escherichia coli O104:H4 pAA plasmid and novel insights into its virulence gene expression and regulation. Sci Rep 6:35307. DOI: 10.1038/srep35307

Wang X, Su R, Guo Q, Liu J, Ruan B, and Wang G. 2019. Competing endogenous RNA (ceRNA) hypothetic model based on comprehensive analysis of long non-coding RNA expression in lung adenocarcinoma. PeerJ 7:e8024. DOI: 10.7717/peerj.8024

Alkan F, Wenzel A, Anthon C, Havgaard JH, and Gorodkin J. 2018. CRISPR-Cas9 off-targeting assessment with nucleic acid duplex energy parameters. Genome Biol 19:177. DOI: 10.1186/s13059-018-1534-x

Brune T, Kunze-Schumacher H, and Kolling R. 2019. Interactions in the ESCRT-III network of the yeast Saccharomyces cerevisiae. Curr Genet 65: 607-619. DOI: 10.1007/s00294-0180915-8

Yoo BC, Yadav NS, Orozco EM. Jr., and Sakai H. 2020. Cas9/gRNA-mediated genome editing of yeast mitochondria and Chlamydomonas chloroplasts. PeerJ 8: e8362. DOI: $10.7717 /$ peerj. 8362

Drost J, van Jaarsveld RH, Ponsioen B, Zimberlin C, van Boxtel R, Buijs A, Sachs N, Overmeer RM, Offerhaus GJ, Begthel H, Korving J, van de Wetering M, Schwank G, Logtenberg M, Cuppen E, Snippert HJ, Medema JP, Kops GJ, Clevers H. 2015. Sequential cancer mutations in cultured human intestinal stem cells. Nature 521:43-47. DOI: 10.1038/nature14415

Fu Y, Foden JA, Khayter C, Maeder ML, Reyon D, Joung JK, and Sander JD. 2013. Highfrequency off-target mutagenesis induced by CRISPR-Cas nucleases in human cells. Nat Biotechnol 31:822-826. DOI: 10.1038/nbt.2623

Fu Y, Sander JD, Reyon D, Cascio VM, and Joung JK. 2014. Improving CRISPR-Cas nuclease specificity using truncated guide RNAs. Nat Biotechnol 32:279-284. DOI: $10.1038 / \mathrm{nbt} .2808$

Hoang TT, Karkhoff-Schweizer RR, Kutchma AJ, and Schweizer HP. 1998. A broad-host-range Flp-FRT recombination system for site-specific excision of chromosomally-located DNA 
372

373

374

375

376

377

378

379

380

381

382

383

384

385

386

387

388

389

390

391

392

393

394

395

396

397

398

399

400

401

402

403

404

405

406

407

408

409

410

411

sequences: application for isolation of unmarked Pseudomonas aeruginosa mutants. Gene 212:77-86. DOI: 10.1016/s0378-1119(98)00130-9

Hsu PD, Scott DA, Weinstein JA, Ran FA, Konermann S, Agarwala V, Li Y, Fine EJ, Wu X, Shalem O, Cradick TJ, Marraffini LA, Bao G, Zhang F. 2013. DNA targeting specificity of RNA-guided Cas9 nucleases. Nat Biotechnol 31:827-832. DOI: 10.1038/nbt.2647

Jiang W, Bikard D, Cox D, Zhang F, and Marraffini LA. 2013. RNA-guided editing of bacterial genomes using CRISPR-Cas systems. Nat Biotechnol 31:233-239. DOI: $10.1038 /$ nbt. 2508

Jiang Y, Chen B, Duan C, Sun B, Yang J, and Yang S. 2015. Multigene editing in the Escherichia coli genome via the CRISPR-Cas9 system. Appl Environ Microbiol 81:25062514. DOI: 10.1128/AEM.04023-14

Kilby NJ, Snaith MR, and Murray JA. 1993. Site-specific recombinases: tools for genome engineering. Trends Genet 9:413-421. DOI: 10.1016/0168-9525(93)90104-p

Liu W, Li J, Bao J, Li X, Guan W, Yuan C, Tang J, Zhao Z, and Shi D. 2015. Simultaneous oral immunization of mice with live attenuated Escherichia coli expressing LT192-STa 13 and LT 192-STb fusion immunogen, respectively, for polyvalent vaccine candidate. Appl Microbiol Biotechnol 99:3981-3992. DOI: 10.1007/s00253-014-6302-6

Yuan C, Liu W, Guan W, Meng X, Tang J, Li X, Zhao Z, and Shi D. 2014. Isolation of Type II Heat-labile Enterotoxin-producing Escherichia coli and Preparation of the Recombinant Toxin. Acta Veterinaria et Zootechnica Sinica 45:1336-1341. DOI: 10.11843/j.issn.03666964.2014.08.019 (Published in China)

Mali P, Aach J, Stranges PB, Esvelt KM, Moosburner M, Kosuri S, Yang L, and Church GM. 2013. CAS9 transcriptional activators for target specificity screening and paired nickases for cooperative genome engineering. Nat Biotechnol 31:833-838. DOI: 10.1038/nbt.2675

Pyne ME, Moo-Young M, Chung DA, and Chou CP. 2015. Coupling the CRISPR/Cas9 System with Lambda Red Recombineering Enables Simplified Chromosomal Gene Replacement in Escherichia coli. Appl Environ Microbiol 81:5103-5114. DOI: 10.1128/AEM.0124815

Sander JD, and Joung JK. 2014. CRISPR-Cas systems for editing, regulating and targeting genomes. Nat Biotechnol 32:347-355. DOI: 10.1038/nbt.2842

Shen Z, Zhang X, Chai Y, Zhu Z, Yi P, Feng G, Li W, and Ou G. 2014. Conditional knockouts generated by engineered CRISPR-Cas9 endonuclease reveal the roles of coronin in C. elegans neural development. Dev Cell 30:625-636. DOI: 10.1016/j.devcel.2014.07.017

Varshney GK, Carrington B, Pei W, Bishop K, Chen Z, Fan C, Xu L, Jones M, LaFave MC, Ledin J, Sood R, Burgess SM. 2016. A high-throughput functional genomics workflow based on CRISPR/Cas9-mediated targeted mutagenesis in zebrafish. Nat Protoc 11:23572375. DOI: $10.1038 /$ nprot.2016.141

Yang X, Xiao Z, Liu F, Chen S, Tang W, Zhang D, and Liu S. 2016. Enterotoxigenic Escherichia coli infection alters intestinal immunity in mice. Mol Med Rep 14:825-830. DOI: $10.3892 / \mathrm{mmr} .2016 .5302$ 
412 Yin X, Biswal AK, Dionora J, Perdigon KM, Balahadia CP, Mazumdar S, Chater C, Lin HC, 413 Coe RA, Kretzschmar T, Gray JE, Quick PW, Bandyopadhyay A. 2017. CRISPR-Cas9 414 and CRISPR-Cpf1 mediated targeting of a stomatal developmental gene EPFL9 in rice. $415 \quad$ Plant Cell Rep 36:745-757. DOI: 10.1007/s00299-017-2118-Z 416 Zhang XH, Tee LY, Wang XG, Huang QS, and Yang SH. 2015. Off-target Effects in 417 CRISPR/Cas9-mediated Genome Engineering. Mol Ther Nucleic Acids 4:e264. DOI: $418 \quad 10.1038 /$ mtna.2015.37

419 Zhao D, Yuan S, Xiong B, Sun H, Ye L, Li J, Zhang X, and Bi C. 2016. Development of a fast 420 and easy method for Escherichia coli genome editing with CRISPR/Cas9. Microb Cell Fact 15:205. DOI: 10.1186/s12934-016-0605-5 


\section{Table $\mathbf{1}$ (on next page)}

Strains and plasmids used in this study ${ }^{a}$

a bla, kan and aadA, represent resistance genes of ampicillin, kanamycin and spectinomycin, respectively; sgRNA-eltl, sgRNA with an N20 sequence for targeting eltl gene; $\Delta e l t \mid(1,173 \mathrm{bp})$, editing template for an 1,173-bp eltl deletion; $\triangle$ estB (220), editing template for a 220-bp estB deletion; $\Delta$ eltllc1 $1_{(400)}$ (1,136), editing template for a 1,136-bp eltllc1 deletion with 400-bp homology arm; $\Delta$ estA(221), editing template for a 221-bp estA deletion; $\Delta$ faeG (474), editing template for a 474-bp faeG deletion; $\Delta$ estB (220)::estA (505), editing template for a 220-bp estB deletion with a 505-bp estA insertion; $\Delta$ eltllc1 (477 bp)::faeG (234), editing template for a 477-bp partial eltllc1 deletion with a 234-bp faeG insertion; $\Delta f a e G(234):: e l t l l c 1^{193}(477)$, editing template for a 234-bp faeG deletion, with a 477-bp eltllc1 ${ }^{193}$ insertion which contains the mutation of the 193rd amino acid of $L T-I / C 1 ; \Delta e / t \| C 1_{(300)}(1,136)$, editing template for a 1,136-bp eltllc1 deletion with 300-bp homology arm; $\Delta$ eltllc1 $_{(200)}(1,136)$, editing template for a 1,136-bp eltllc1 deletion with 200-bp homology arm; $\Delta$ eltlll ${ }_{(100)}(1,136)$, editing template for a 1,136-bp elttlc1 deletion with 100-bp homology arm; $\Delta \operatorname{seltllc1}_{(50)}(1,136)$, editing template for a 1,136-bp eltllc1 deletion with 50-bp homology arm. The length of the homology arm in this article refers to the length of one side. Donor primers were used to amplify homologous arms. 


\begin{tabular}{|c|c|c|}
\hline $\begin{array}{l}\text { Strains and } \\
\text { plasmids }\end{array}$ & Characteristics & Source or reference \\
\hline E. coli Trans1-T1 & $\begin{array}{l}\mathrm{F}-\phi 80(\text { lac } \mathrm{Z}) \Delta \mathrm{M} 15 \Delta l a c \mathrm{X} 74 h s d \mathrm{R}\left(\mathrm{r}_{\mathrm{k}}^{-}\right. \\
\left.\mathrm{m}_{\mathrm{k}}^{+}\right) \Delta r e c \mathrm{~A} 1398 \text { endA1ton } \mathrm{A}\end{array}$ & TransGen Biotech \\
\hline E. coli $\mathrm{O} 141: \mathrm{K} 85$ & elt $I$, est $B, f a e G$ & CVCC197 \\
\hline E. coli $\mathrm{DN} 1502$ & elt IIcl & $\begin{array}{l}\text { This laboratory(Liu } \\
\text { et al. 2015) }\end{array}$ \\
\hline E. coli $\mathrm{O} 142$ & estA & $\begin{array}{l}\text { This } \\
\text { laboratory(Yuan et } \\
\text { al. 2014) }\end{array}$ \\
\hline pMD19T & bla & Taraka \\
\hline pCas & kan, $\operatorname{Cas} 9$, araC, Gam, Bet, Exo, repA101 & $\begin{array}{l}\text { Kindly provided by } \\
\text { Pro. Yang Sheng }\end{array}$ \\
\hline pTargetF & sgRNA, aadA, $p M B 1$ & $\begin{array}{l}\text { Kindly provided by } \\
\text { Pro. Yang Sheng }\end{array}$ \\
\hline pTarget- $\Delta e l t I$ & aadA, $p M B 1$, sgRNA-elt $I, \Delta$ elt I (1,173 bp) & This study \\
\hline pTarget- $\triangle e s t B$ & aadA, $p M B 1, \operatorname{sgRNA}-e s t B, \triangle e s t B(220)$ & This study \\
\hline $\begin{array}{l}\text { pTarget- } \\
\Delta \text { elt IIc1 } 1_{(400)}\end{array}$ & $\begin{array}{l}\text { aadA, } p M B 1, \quad \text { sgRNA-elt IIc1, } \Delta \text { elt IIc } 1_{(400)} \\
(1,136)\end{array}$ & This study \\
\hline pTarget- $\Delta e s t A$ & aadA, $p M B 1$, sgRNA-est $A, \Delta e s t A(221)$ & This study \\
\hline pTarget- $\Delta f a e G$ & aadA, $p M B 1, \operatorname{sgRNA}-f a e G, \Delta f a e G(474)$ & This study \\
\hline $\begin{array}{l}\text { pTarget- } \\
\Delta e s t B:: e s t A\end{array}$ & $\begin{array}{l}\text { aadA, pMB1, sgRNA-estB, } \Delta \text { estB (220)::estA } \\
\text { (505) }\end{array}$ & This study \\
\hline pTarget- & aadA, $p M B 1$, sgRNA-elt IIcl, $\Delta$ elt IIc $1^{\mathrm{p}}(477$ & This study \\
\hline$\Delta e l t$ IIc $1^{\mathrm{p}}:: f a e G$ & bp)::faeG (234) & \\
\hline
\end{tabular}




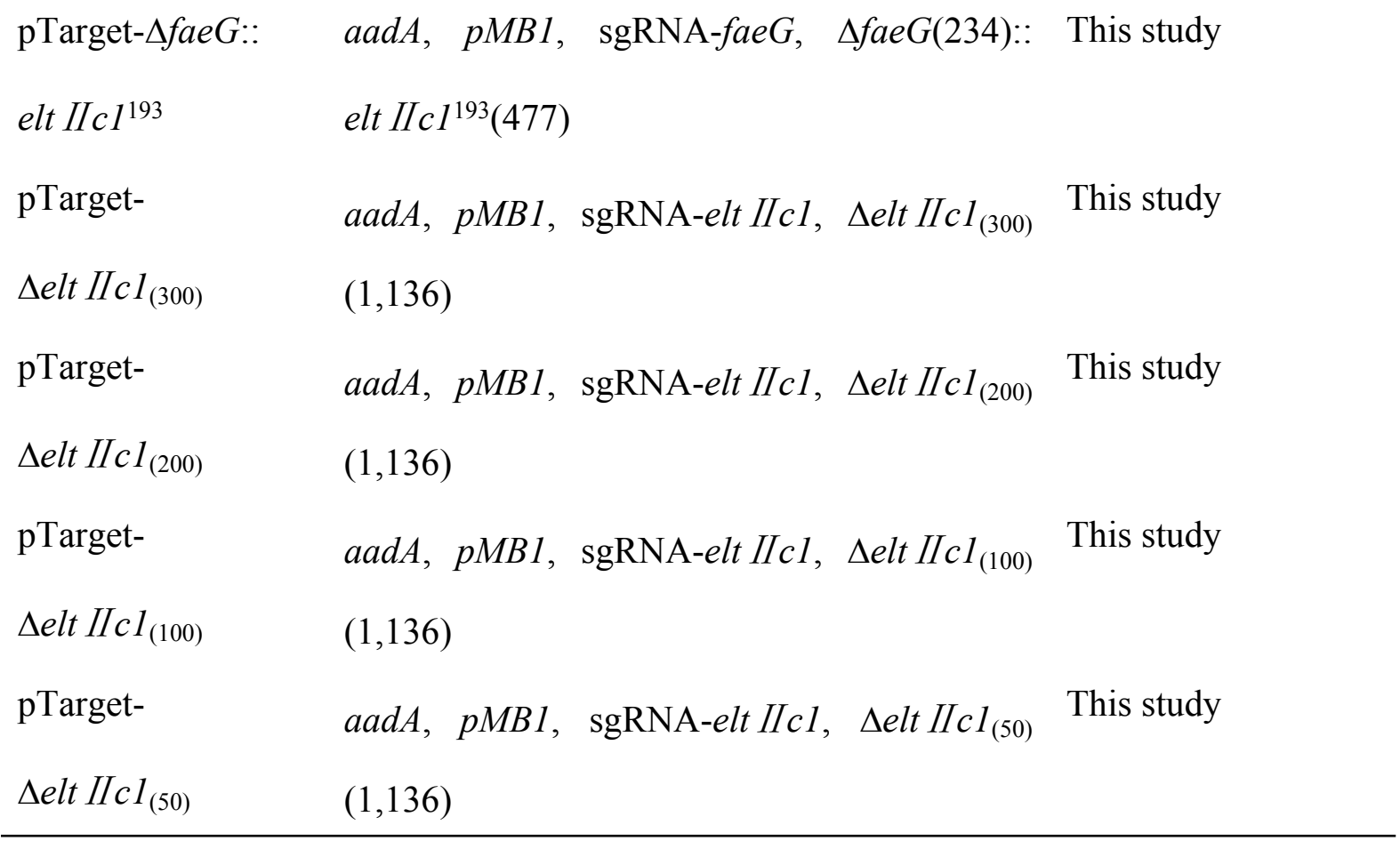




\section{Table 2 (on next page)}

Mutation efficiency of pCas/pTarget system

Experiments 1, eltl was deleted from E. coli O141:K85. Experiments 2, estB was deleted from E. coli 0141:K85. Experiments 3, estB was deleted from 0141:K85Aeltl. Experiments 4, faeG was deleted from E. coli O141:K85. Experiments 5, faeG was deleted from E. coli 0141:K85Delt/LestB. Experiments 6, estA was replaced in estB loci in E. coli 0141:K85. Experiments 7, estA was deleted from E. coli O142. Experiments 8, eltllc1 was deleted from DN1502 with 400 bp homology arm. Experiments 9-10, the codon of the 193rd amino acid (leucine) of eltIIC1 was changed from CTG to CTC. Experiments 11-14, eltIIC1 was deleted from DN1502 with different length of homology arms. 


\begin{tabular}{|c|c|c|c|c|c|c|}
\hline $\begin{array}{c}\text { Expt. } \\
\text { no. }\end{array}$ & $\begin{array}{l}\text { Targetin } \\
\mathrm{g} \\
\text { genome } \\
\text { locus of } \\
\text { sgRNA } \\
\end{array}$ & $\begin{array}{l}\text { Host } \\
\text { cell }\end{array}$ & $\begin{array}{l}\text { Plasmid } \\
\text { pTarget }\end{array}$ & $\begin{array}{c}\text { Length of } \\
\text { homology arm } \\
\text { (left, right) } \\
\text { (bp) }\end{array}$ & $\begin{array}{c}\text { Number of } \\
\text { picked } \\
\text { colonies/re } \\
\text { combinant } \\
\text { colonies }\end{array}$ & $\begin{array}{c}\text { Mutation } \\
\text { efficiency } \\
(\%)\end{array}$ \\
\hline 1 & elt I & $\begin{array}{c}\text { E. coli } \\
\text { O141:K } \\
85\end{array}$ & $\begin{array}{c}\text { pTarget- } \\
\text { selt I }\end{array}$ & 137,132 & $50 / 2$ & 4.00 \\
\hline 2 & est $B$ & $\begin{array}{c}\text { E. coli } \\
\text { O141:K } \\
\quad 85\end{array}$ & $\begin{array}{c}\text { pTarget- } \\
\Delta e s t B\end{array}$ & 167,226 & $68 / 1$ & 1.40 \\
\hline 3 & est $B$ & $\begin{array}{c}\text { E. coli } \\
\text { O141:K } \\
85 \Delta e l t \\
I\end{array}$ & $\begin{array}{c}\text { pTarget- } \\
\Delta e s t B\end{array}$ & 167,226 & $85 / 15$ & 17.64 \\
\hline 4 & faeG & $\begin{array}{c}\text { E. coli } \\
\text { O141:K } \\
\quad 85\end{array}$ & $\begin{array}{c}\text { pTarget- } \\
\Delta \text { faeG }\end{array}$ & 203,202 & $21 / 5$ & 23.80 \\
\hline 5 & faeG & $\begin{array}{c}\text { E. coli } \\
\mathrm{O} 141: \mathrm{K} \\
85 \Delta e l t \\
I \\
\Delta e s t B\end{array}$ & $\begin{array}{c}\text { pTarget- } \\
\Delta \text { faeG }\end{array}$ & 203,202 & $50 / 2$ & 4.00 \\
\hline 6 & estB & $\begin{array}{c}\text { E. coli } \\
\text { O141:K } \\
85\end{array}$ & $\begin{array}{c}\text { pTarget- } \\
\Delta \text { est } B:: \\
\text { estA }\end{array}$ & 167,226 & $99 / 14$ & 14.14 \\
\hline 7 & estA & $\begin{array}{c}\text { E. coli } \\
\text { O142 }\end{array}$ & $\begin{array}{c}\text { pTarget- } \\
\Delta \text { estA }\end{array}$ & 112,101 & $115 / 9$ & 7.80 \\
\hline 8 & elt $\Pi_{c 1}$ & $\begin{array}{l}\text { E. coli } \\
\text { DN150 } \\
2\end{array}$ & $\begin{array}{l}\text { pTarget- } \\
\Delta e l t I I C 1 \\
\quad(400)\end{array}$ & 404,465 & $75 / 51$ & 68 \\
\hline 9 & elt $I_{C} 1$ & $\begin{array}{c}\text { E. coli } \\
\text { DN150 } \\
\quad 2\end{array}$ & $\begin{array}{l}\text { pTarget- } \\
\Delta e l t \text { II } 1 \\
\mathrm{p}_{:}: \text {faeG }\end{array}$ & 309,428 & $40 / 36$ & 90 \\
\hline 10 & faeG & $\begin{array}{c}\text { E. coli } \\
\text { DN150 } \\
2 \Delta\end{array}$ & $\begin{array}{l}\text { pTarget- } \\
\Delta \text { fae } G:\end{array}$ & 309,428 & $20 / 20$ & 100 \\
\hline
\end{tabular}


2

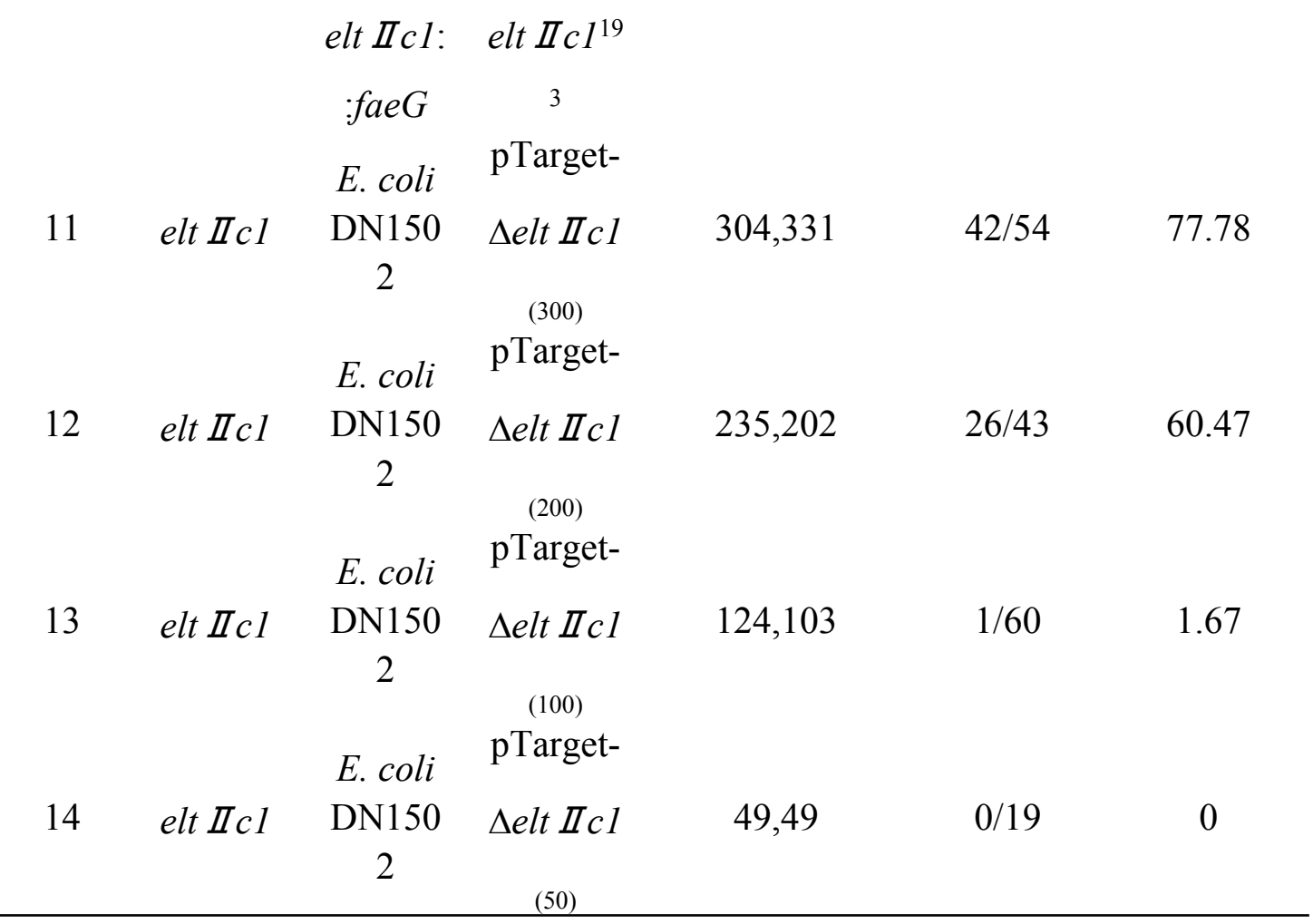




\section{Table 3(on next page)}

N20+PAM sequence and GenBank ID

a Primers for virulence genes and N20 are designed according to the GenBank ID in the table. 
1

\begin{tabular}{ccc}
\hline Target gene & N20+PAM & GenBank \\
\hline elt $I$ & AAGCTTGGAGAGAAGAACCC TGG & CP002732.1 \\
elt $\boldsymbol{I} \boldsymbol{c} \boldsymbol{}$ & TCTTTTGGTGCGATA GAAGG GGG & JQ031705.1 \\
estB & CAAATAATGGTTGCAGCAAA AGG & AY028790.1 \\
faeG & GCCGGTGTGTTCGGGAAAGG TGG & V00292.1 \\
est $A$ & TGTTGTAATCCTGCCTGTGC TGG & V00612.1 \\
\hline
\end{tabular}

2 


\section{Figure 1}

Gene editing theory.

(A) First, the host strain to be mutagenized is transformed with pCas expressing the $\lambda$ Red component (Exo, Bet, Gam), the Cas9 endonuclease, and tracrRNA. Next, the host strain containing pCas is transformed with pTarget series carrying donor DNA and encoding the gRNA that specifies the site of cleavage. The gRNA directs the Cas9 endonuclease to the cleavage site. (B)While the gRNA recognizing 20 bases of the target site, the Cas9 mediates bacterial DNA double strand break (DSB). DSB is repaired by $\lambda$ Red homologous recombination. 

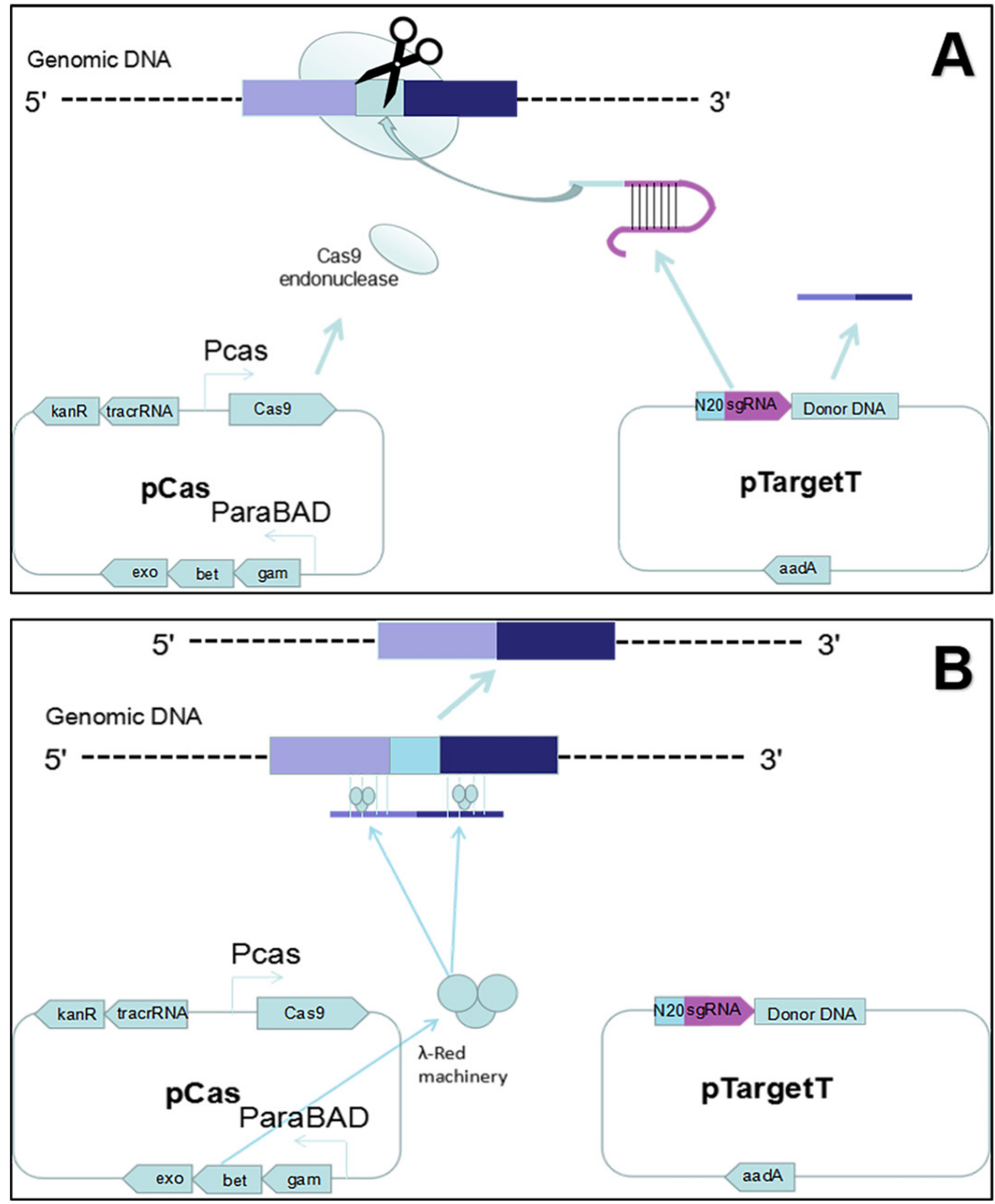
Figure 2

Gene editing and plasmid curing process.

Step I: pCas was introduced into the host cell. Step II: pTarget was introduced into the host cells harboring pCas. Step III: Targeted gene of the host cells was recombined. Step IV: pTarget was cured with IPTG and cultured recombined cells at $30^{\circ} \mathrm{C}$. Step V: pCas was cured by cultured recombined cells at $37^{\circ} \mathrm{C}$.
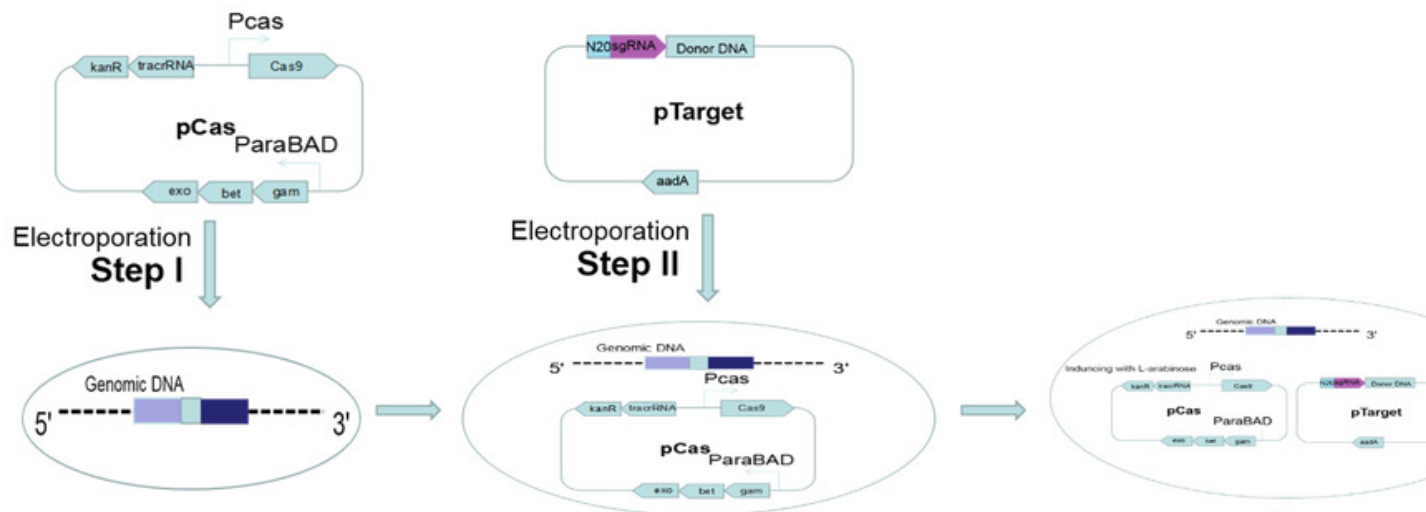

Recombination Step III
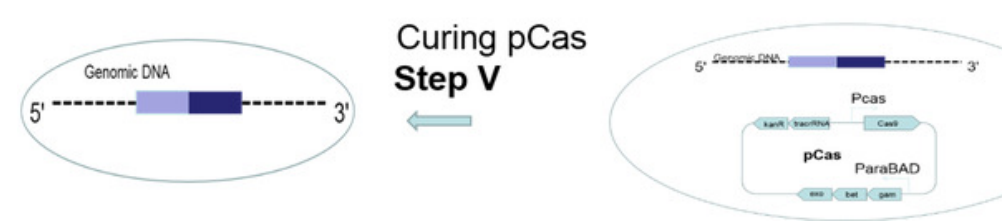

Curing pTarget Step IV

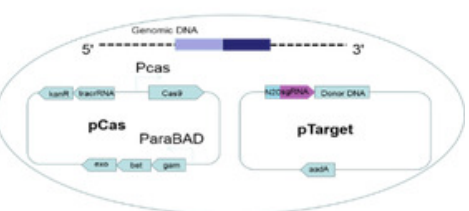




\section{Figure 3}

Agarose gel electrophoresis of colony PCR for different genes and Sacl digestion.

(A) Identification of eltl gene knockout with primers P7 / P8. Lane 1, positive control. Lane 2, Negative control. (B) Identification of estB gene knockout with primers P15/P16. Lane 1, positive control. Lane 2, Negative control. (C) Identification of faeG gene knockout with primers P39/P40. Lane 1, positive control. Lane 2, Negative control. (D) Identification of eltllc1 gene knockout with primers P23/P24. Lane 1, positive control. (E) Identification of estA inserted into estB with primers P15/P16. Lane 1, positive control. Lane 2, Negative control. (F) Identification of estA gene knockout with primers P31/P32. Lane 1, positive control. Lane 2, Negative control. (G) Identification of faeG inserted into eltllc1 with primers P54/P55. Lane 1, positive control. Lane 2, Negative control. (H) Identification of eltllc $1^{193}$ gene single base mutation with primers P54/P55. Lane 1, positive control. Lane 2, Negative control. (I) Lane 1, eltllc1 ${ }^{193}$ of the corrected recombinant ETEC was amplified with primers P23/P24. Lane 2, amplified fragment was digested with Sacl for $3 h$. 

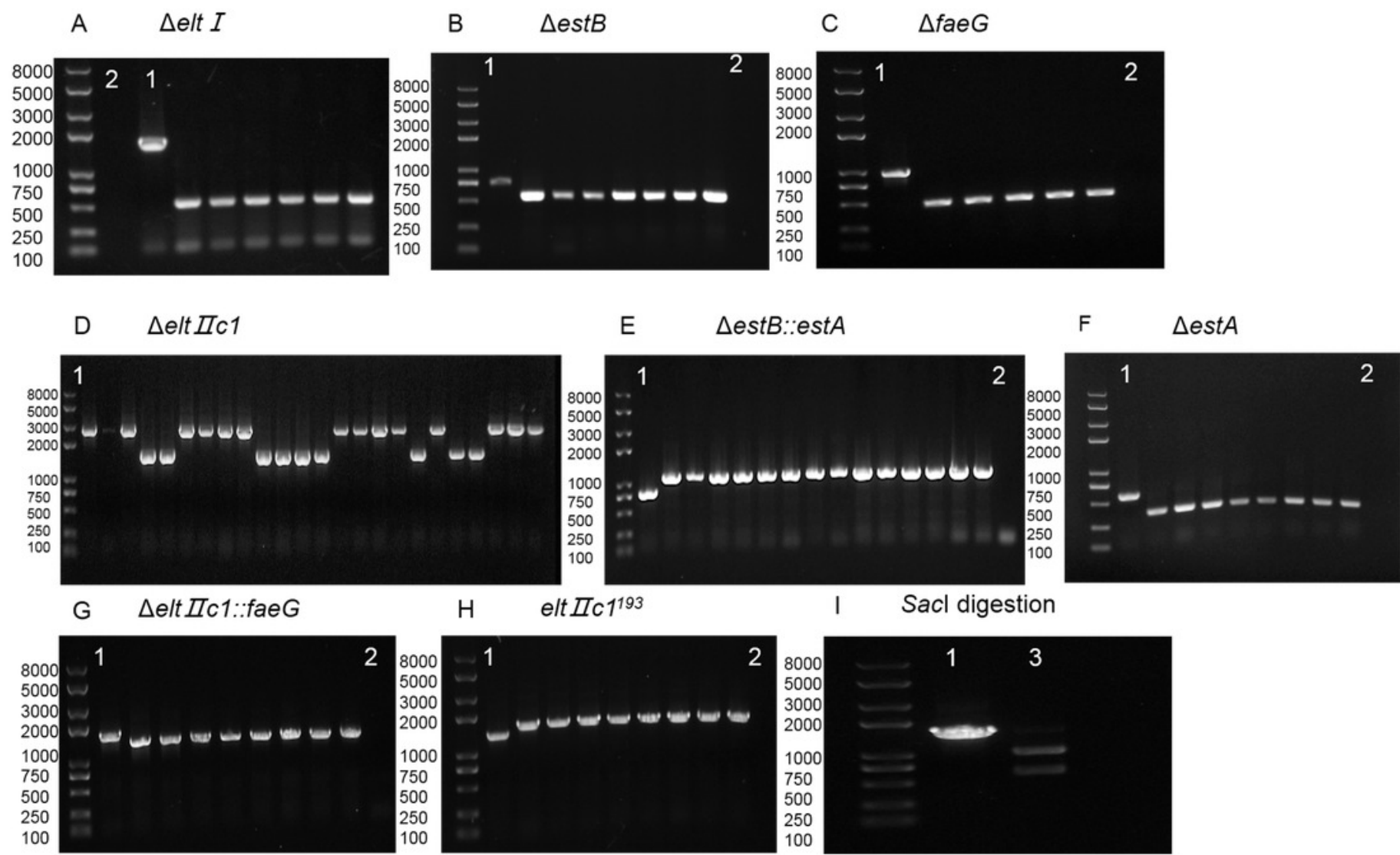

$\mathrm{H} \quad$ elt $\Pi c 1^{193}$

I Sacl digestion
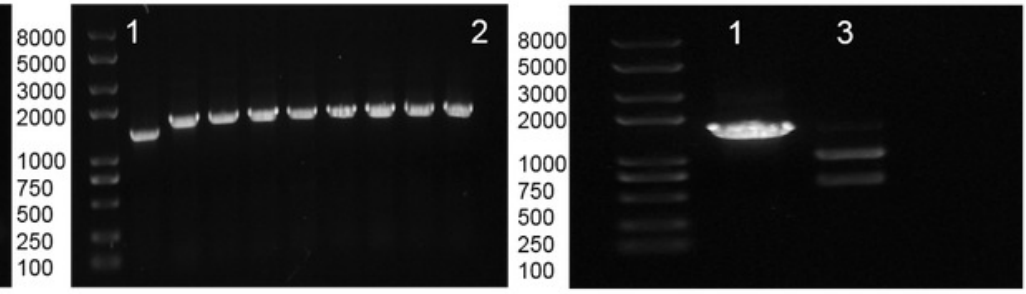


\section{Figure 4}

Agarose gel electrophoresis of colony PCR after curing the plasmids.

(A) Verification of eltl gene knockout and plasmid curing. (B) Verification of eltllc1 gene knockout and plasmid curing. (C) Verification of estB gene knockout and plasmid curing. (D) Verification of estA inserted into estB and plasmid curing. (E) Verification of faeG inserted into eltllc1 and plasmid curing. (F) Verification of eltllc1 $1^{193}$ gene single base mutation and plasmid curing. (G) Verification of faeG gene knockout and plasmid curing. (H) Verification of estA gene knockout and plasmid curing. Region 1: Verification of editing fragments after curing the plasmids. Region 2: Verification of pTarget series after curing with IPTG, using primers P68/69. Region 3: Verification of pCas after curing with temperature sensitive replicon, using primers P70/P71. The first three lanes in each region are genetically edited ETEC. The fourth is a positive control and the fifth is a negative control. 
A $\Delta$ elt I

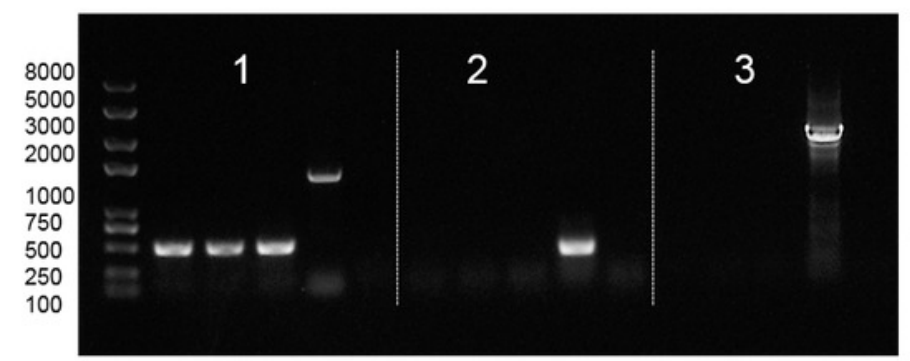

C $\Delta$ estB

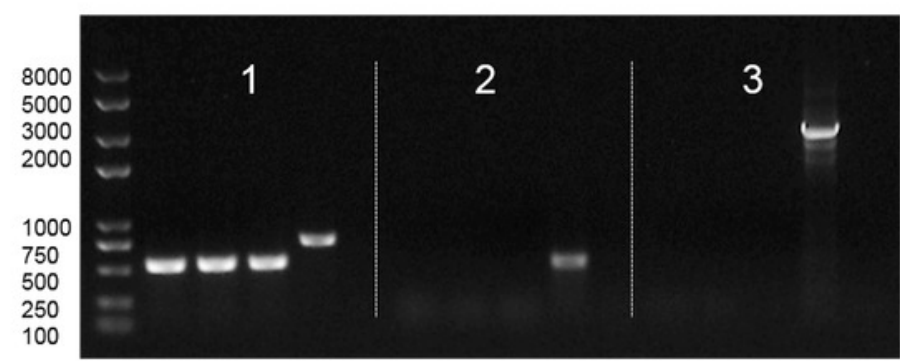

E $\Delta$ elt $\Pi c 1:: f a e G$

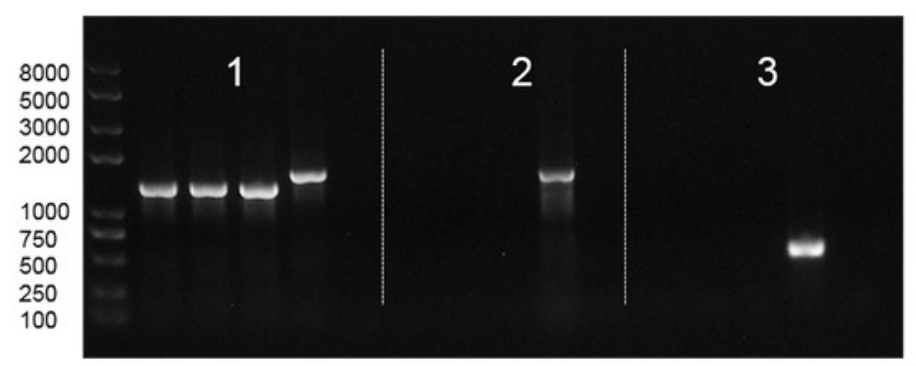

G $\Delta$ faeG

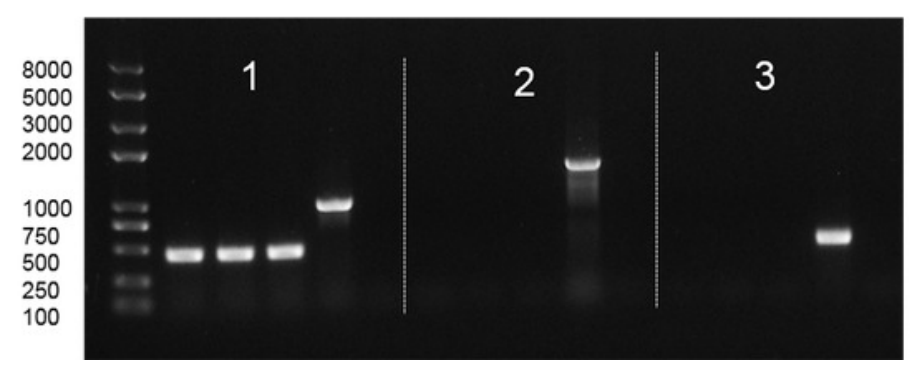

B $\Delta e l t \Pi c 1$

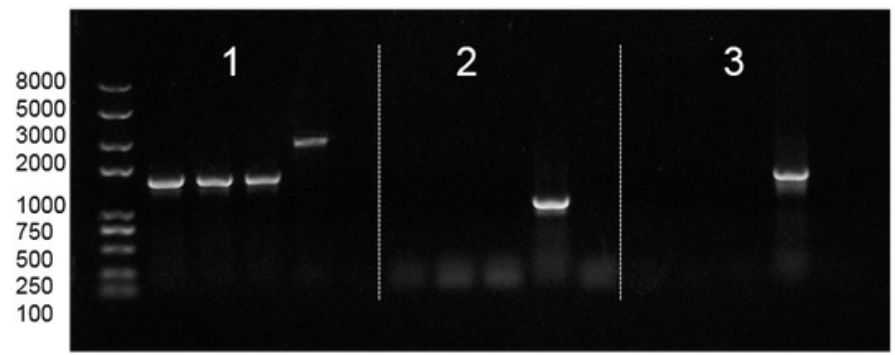

D $\Delta$ estB::estA

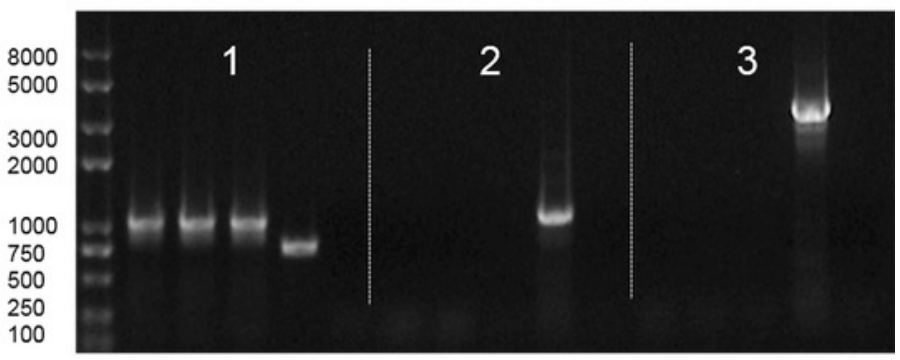

$\mathrm{F}$ elt $\amalg c 1^{193}$

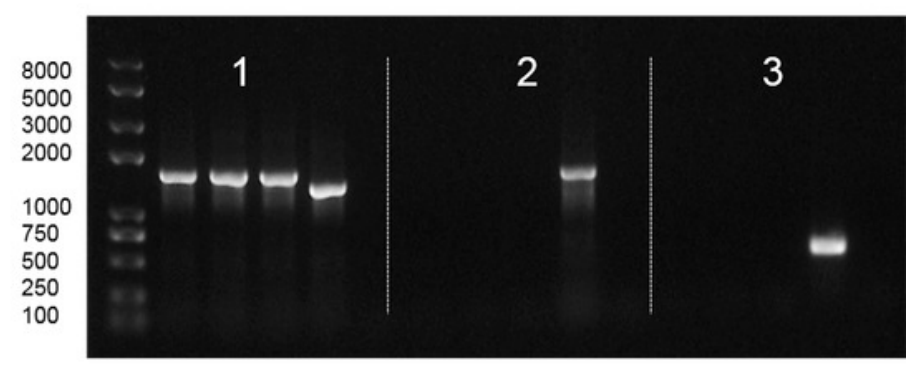

H $\Delta$ estA

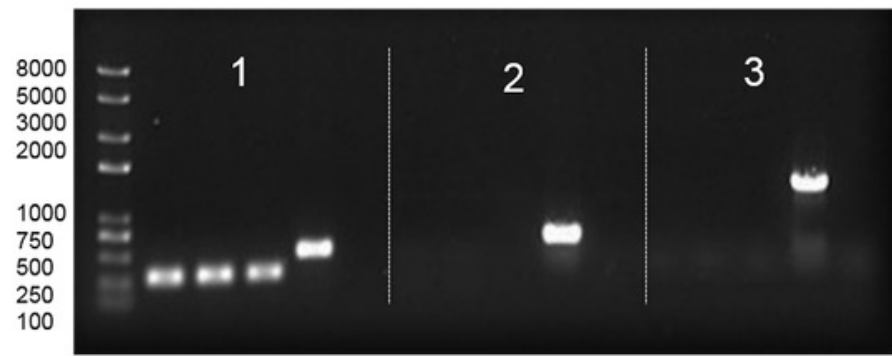

